\title{
PRODUÇÃO DE ANTICORPOS POLICLONAIS ANTI-RICINA
}

\author{
Production of polyclonal anti-ricin antibodies
}

\author{
Roselayne Ferro Furtado ${ }^{1}$, Maria Izabel Florindo Guedes ${ }^{2}$, Carlucio Roberto Alves ${ }^{3}$, \\ Ana Cristina de Oliveira Monteiro Moreira ${ }^{4}$, Wagner Pereira Felix ${ }^{5}$, Rosa Amália Fireman Dutra ${ }^{6}$
}

\begin{abstract}
RESUMO
A ricina é uma proteína bastante tóxica presente nas sementes de mamona que impossibilita o uso da torta de mamona "in natura", como ração. A torta de mamona destoxificada necessita ainda de métodos de análise que garantam a ausência de traços dessa proteína. Objetivou-se, neste trabalho, produzir e avaliar a sensibilidade e especificidade de anticorpos policlonais anti-ricina, para serem empregados como possíveis componentes de métodos sorológicos na detecção de ricina em torta de mamona destoxificada. Foram avaliadas três doses da proteína: 400, 180 e $100 \mu \mathrm{g}$ cada uma dividida em duas aplicações em coelhos. A primeira dose foi injetada no animal no início do experimento e a segunda após 21 dias. O método de ELISA indicou que as duas doses menores (100 e $180 \mu \mathrm{g}$ ) induziram respostas imunológicas primária e secundária com produção de anticorpos específicos. Enquanto a dose maior $(400 \mu \mathrm{g})$ de ricina apresentou uma resposta primária com elevação dos títulos de anticorpos, seguida de uma supressão da resposta. Esse perfil é sugestivo de tolerância imunológica. Pela técnica de Western blotting verificou-se que os anticorpos policlonais produzidos são bastante específicos para a ricina, no entanto, por detectarem ricina na forma nativa e desnaturada não são recomendados para o monitoramento de ricina em torta de mamona destoxificada por tratamento térmico.
\end{abstract}

Termos para indexação: Ricinus communis, toxicidade, detecção.

\section{ABSTRACT}

Ricin is a very toxic protein found in castor bean plants, making it impossible to use natural castor cake as animal food. The detoxificated castor cake needs to be analyzed by methods that ensure the absence of traces of this protein. This work had the objective to produce and to evaluate the sensitivity and specificity of anti-ricin polyclonal antibodies, to be employed as component of sorologic methods as the ELISA in the detection of ricin in detoxificated castor cake. Three doses of protein, $400,180 \mathrm{and} 100 \mu \mathrm{g}$ were evaluated each one injected twice into rabbit, with one half in the begin of the experiment and the other half after 21 days of immunization. The ELISA method indicated that the lower doses $(100 \mathrm{e} 180 \mu \mathrm{g})$ induced primary and secondary immunological response with production of specific antibodies, while the higher dose of ricin $(400 \mu \mathrm{g})$ showed a primary response with increase of the antibody titre, followed of immunological suppression. This profile suggests immunological tolerance. By Western blotting technique it was verified that polyclonal antibodies are too specific to ricin, however, they detected ricin in native and denaturated form and are not recommended for the monitoring of ricin in detoxificated castor bean cake by heat treatment.

Index terms: Ricinus communis, toxicity, detection.

(Recebido em 12 de janeiro de 2009 e aprovado em 17 de julho de 2009)

\section{INTRODUÇÃO}

A torta de mamona é um produto altamente proteico gerado em grande quantidade na produção do biodiesel. $\mathrm{Na}$ torta são encontradas proteínas nocivas, como o complexo alergênico, aglutininas e a ricina, mas o complexo alergênico não afeta animais, apenas humanos (Anandam et al., 2005; Ogunniyi, 2006; Barnes et al., 2009) e as aglutininas são mais facilmente degradadas com o aumento da temperatura do que a ricina. A ricina é uma proteína tóxica, inativadora de ribossomos e, por conseguinte, bloqueadora da síntese proteica, presente no endosperma de sementes de mamona (Ricinus communis L.), constituída por duas cadeias ligadas entre si por uma ponte dissulfeto (Lord et al., 1994; Olsnes \& Kozlov, 2001).

A torta de mamona possui cerca de $42,5 \%$ de proteína bruta, $20 \%$ de fibra e $0,78 \%$ de fósforo entre outros componentes de grande importância nutricional (Costa et al., 2004). O alto valor proteico da torta de mamona tornaa atraente como alternativa para ração, porém a presença das proteínas tóxicas presentes na semente têm inviabilizado esse uso, tornando-a recomendada apenas

\footnotetext{
${ }^{1}$ Empresa Brasileira de Pesquisa Agropecuária/Embrapa - Agroindústria Tropical - Rua Doutora Sara Mesquita - 2270 - Planalto Pici - 60511-110 Fortaleza, CE - roselayne@cnpat.embrapa.br

2Universidade Estadual do Ceará/UECE - Departamento de Nutrição - Fortaleza, CE

3Universidade Estadual do Ceará/UECE - Departamento de Química - Fortaleza, CE

${ }^{4}$ Universidade de Fortaleza/Unifor - Diretoria do Centro de Ciências da Saúde - Fortaleza, CE

${ }^{5}$ Universidade Federal do Vale do São Francisco/UNIVASF - Petrolina, PE

${ }^{6}$ Universidade Estadual de Pernambuco/UPE - Instituto de Ciências Biológicas - Recife, PE
} 
como adubo orgânico. Em vista disso, a destoxificação, seja por processos químicos, físicos ou químicos-físicos é um procedimento indispensável para a viabilização da torta de mamona como ração, haja vista que a toxicidade da ricina é bastante alta. Pela via oral, a toxicidade da proteína é menor, quando comparada a outras vias de administração de drogas, provavelmente, devido à pobre adsorção e digestão enzimática no trato digestivo (Franz \& Jaax, 1997). Pela via parenteral, a toxicidade é cerca de cem vezes maior.

Considerando a importância da destoxificação completa da torta de mamona para a segurança no consumo da torta de mamona por animais, recomenda-se uma análise rápida quanto à presença de ricina que ateste a atoxicidade da torta a cada processo de destoxificação, visto que o procedimento pode não ter sido satisfatoriamente realizado e quantidades mínimas da proteína são suficientes para conduzir animais a óbito.

O método imunoenzimático ELISA apresenta características como alta sensibilidade e baixo custo (Beserra Júnior, et al., 2009) que o torna adequado para detecção de ricina em torta de mamona submetida a processo de destoxificação. Neste sentido, anticorpos antiricina devem ser produzidos para utilização no método de ELISA e futuras aplicações em kits comerciais.

Nos ensaios de produção de anticorpos anti-ricina, a padronização da dose e a via de administração de ricina devem ser estudados com cautela para garantir uma satisfatória produção de anticorpos e a vida dos animais utilizados no experimento.

Em ensaios com coelhos, a administração de ricina diminuiu a pressão sanguínea e aumentou o batimento cardíaco e fluxo de sangue para tecidos e órgãos nos estágios mais precoces da intoxicação e causou hemorragia e necrose no coração no estágio terminal (Zhang et al., 1994). A dose letal de ricina injetada para coelhos é de aproximadamente $0,5 \mathrm{mg} / \mathrm{kg}$ (Gardner et al., 1960). Sementes de mamona trituradas de Ricinus communis administradas em dose única por sonda intragástrica em coelhos, causou sintomas de intoxicação e letalidade na concentração de $1 \mathrm{~g} / \mathrm{kg}$ e $2 \mathrm{~g} / \mathrm{kg}$ (Brito \& Tokarnia, 1996).

Objetivou-se, neste trabalho, imunizar coelhos pela via subcutânea, a partir de gel de policrilamida, para a produção de anticorpos anti-ricina e avaliar a sensibilidade e especificidade desses pelo método de ELISA e técnica de Western blot, respectivamente.

\section{MATERIAL E MÉTODOS}

\section{Obtenção da ricina}

Amostra de sementes de mamona da cultivar Nordestina desenvolvida pela Embrapa Algodão foram utilizadas para a obtenção da torta de mamona. As sementes foram trituradas, prensadas e deixadas em repouso com hexano durante a noite para retirada do óleo residual. Após evaporação do solvente, a torta de mamona, propriamente dita, foi diluída em $\mathrm{NaCl} 0,15 \mathrm{M}$ na proporção de 1:10 e homogeneizada por 30 minutos. Posteriormente, centrifugouse a solução a $32.980 \times$ g por 20 minutos em temperatura de $4^{\circ} \mathrm{C}$ para separação e coleta do sobrenadante.

$\mathrm{O}$ sobrenadante foi filtrado e submetido à coluna de cromatografia de afinidade de goma de guar, preparada segundo Appukuttan et al. (1977). As cromatografias de afinidade foram realizadas à temperatura ambiente $26^{\circ} \pm 1^{\circ} \mathrm{C}$ e o fluxo das frações foi de $0,6 \mathrm{~mL} /$ minuto As frações foram eluídas com solução de glicina $0,1 \mathrm{M} \mathrm{e} \mathrm{NaCl} \mathrm{0,15} \mathrm{M} \mathrm{pH} \mathrm{2,6} \mathrm{e}$ dialisadas contra água para remoção da glicina. Após diálise, a solução foi concentrada por liofilização. O material liofilizado foi avaliado para comprovar a purificação da proteína de interesse (cerca de $66 \mathrm{kDa}$ ) por eletroforese em gel de poliacrilamida $12 \%$.

\section{Produção dos anticorpos policlonais}

Para a produção dos anticorpos, três coelhos da raça Nova Zelândia de cerca de cinco meses foram imunizados com ricina desnaturada recortada de gel de poliacrilamida (bandas de cerca de 32 e $34 \mathrm{kDa}$ ), macerada e injetada no animal. Foram avaliadas três doses de ricina $400 \mu \mathrm{g}, 180 \mu \mathrm{g}$ e $100 \mu \mathrm{g}$, cada dose foi avaliada em um coelho. Como controle do ensaio, antes da primeira inoculação, foi feita uma sangria de cerca de $10 \mathrm{~mL}$ para a coleta do soro pré-imune.

Foram realizadas injeções em cada lado na região dos ombros e na região próxima a cada perna $(0,2 \mathrm{~mL}$ em cada região), pela via subcutânea. As doses injetadas inicialmente nos coelhos foram $200 \mu \mathrm{g}, 90 \mu \mathrm{g}$ e $50 \mu \mathrm{g}$. A sangria de cada animal foi feita a cada sete dias para a coleta do soro e três semanas após a primeira imunização, foi aplicado um reforço com a mesma quantidade de proteína inicial. A sangria foi realizada até o $42^{\circ}$ dia após a imunização do animal. O sangue coletado foi deixado coagular por uma hora e o soro foi centrifugado a $4000 \mathrm{x} \mathrm{g}$ por dez minutos para retirada das hemácias e plaquetas remanescentes. Os soros foram armazenados a $-4^{\circ} \mathrm{C}$.

\section{Análise dos anticorpos produzidos}

Para testar a sensibilidade e especificidade dos soros produzidos foi realizada análise pelo método de ELISA e técnica de Western blot, respectivamente. Anticorpos policlonais anti-ricina comerciais da empresa inglesa Abcam foram também analisados pelo método de ELISA. 
No método de ELISA testes preliminares foram realizados para determinar a menor quantidade de ricina a ser utilizada na sensibilização da placa e o melhor tampão de bloqueio na sensibilização de cada poço. Sendo assim, as placas foram sensibilizadas com $0,3 \mu \mathrm{g}$ do antígeno (ricina)/poço e colocadas sobre refrigeração a $4^{\circ} \mathrm{C} \mathrm{em}$ câmara úmida por 16 horas. As placas foram lavadas com PBS Tween $0,05 \%$, após cada tratamento. A seguir foi feito o bloqueio com PBS- BSA (1\%), distribuindo-se $100 \mu \mathrm{L}$ em cada poço e incubação por 1 hora a $37^{\circ} \mathrm{C}$. O soro obtido dos coelhos foi diluído na razão dois, a partir de uma proporção inicial de 1:100 em PBS, até a proporção final de 1:12.800, adicionando $50 \mu \mathrm{L}$ das amostras/poço. As placas foram incubadas em câmara úmida por 2 horas a $37^{\circ} \mathrm{C}$. O conjugado anti IgG marcado com peroxidase foi diluído 1:4000 em PBS e distribuído $50 \mu \mathrm{L}$ do conjugado em todos os poços. A incubação foi feita em câmara úmida por 2 horas a $37^{\circ} \mathrm{C}$. A revelação foi feita com $100 \mu \mathrm{L}$ de solução de SIGMAFAST ${ }^{\mathrm{TM}}$ OPD (o-Phenylenediamine dihydrochloride) (Sigma Aldrich). A reação foi neutralizada com ácido sulfúrico 2,5 N. O estudo do nível de reação dos anticorpos policlonais (sensibilidade) foi realizado a partir da diluição inicial dos anticorpos na proporção 1:100 em duplicata, calculando-se o cut off do ELISA (média das absorbâncias do controle mais 3 vezes o desvio padrão). Consideraram-se as diluições cujas médias de absorbância foram inferiores ao cut off como negativas, e positivas as diluições anteriores com valores acima do cut off (ponto de corte). A partir deste pressuposto, calculou-se o título dos anticorpos.

Para a técnica de Western blotting, foi utilizada membrana de nitrocelulose e gel de poliacrilamida a $12 \%$ em condições desnaturantes e não desnaturantes de amostras de extrato da torta de mamona. A transferência das proteínas do gel para a membrana de nitrocelulose foi realizada utilizando PBS como tampão de transferência e aplicação de $38 \mathrm{~mA}$ e $38 \mathrm{~V}$ por duas horas (Towbin et al., 1979). O bloqueio foi feito com PBS molico ${ }^{\circledR}$ (Nestlé) $5 \%$ e os procedimentos de lavagem e os de aplicação do anticorpo primário, secundário e revelação seguiram os adotados no ELISA, acrescentando apenas o leite desnatado nas diluições com o PBS. Os anticorpos primários foram diluídos em PBS 1:100 e os secundários 1:500. A revelação foi feita com solução de peróxido de hidrogênio $30 \%$, cloreto de níquel e tampão Tris - $\mathrm{HCl}$ pH 7,2.

\section{RESULTADOS E DISCUSSÃO}

Na produção dos anticorpos policlonais anti-ricina vários fatores devem ser considerados entre eles: a dose, a escolha do adjuvante e a via de imunização correta de administração da proteína, sobre o risco de provocar sofrimento e posterior óbito do animal utilizado nos experimentos. Nas pesquisas têm-se mostrado que a ricina pode provocar efeitos adversos no animal como hemorragias no intestino e rins, congestão severa nos pulmões, gastroenterite, cardiomiopatia, entre outros sintomas (Audi et al., 2005; Aslani et al., 2007).

Trabalhos envolvendo a produção de anticorpos policlonais anti-ricina são escassos na literatura, mas de uma forma geral, a metodologia empregada para essa finalidade inclui o uso de adjuvantes como hidróxido de alumínio e adjuvante de Freund (Lipps, 2001). Neste trabalho a poliacrilamida do gel funcionou como adjuvante, induzindo síntese de anticorpos com títulos elevados e não conduziu nenhum animal a óbito e tampouco provocou modificação no comportamento alimentar no animal. Embora a poliacrilamida seja pouco utilizada como adjuvante, na produção de anticorpos o seu uso é particularmente vantajoso, quando a purificação da proteína por outros meios não é prática (Amero et al., 1994). Além disso, esse método permite a potencialização da resposta imunológica, considerando que a poliacrilamida ajuda a reter o antígeno, permitindo que o mesmo seja liberado lentamente, promovendo maior eficiência da apresentação do antígeno ao sistema imune.

A Figura 1, referente à cinética dos anticorpos para a dose de $400 \mu \mathrm{g}$, demonstrou que a síntese de anticorpos ( $\mathrm{IgG}$ ) ocorreu no $7^{\circ}$ dia, tendo seu pico máximo no $14^{\circ}$, sofrendo em seguida uma redução drástica. Observa-se, que mesmo após o reforço, que foi aos 21 dias, não houve alteração na resposta imunológica. Esse tipo de comportamento é típico de tolerância imunológica em que a produção de anticorpo é drasticamente diminuída, embora o antígeno continue estimulando a defesa imunológica por outros mecanismos (Hoyne et al., 2000; Janeway et al., 2007). O fenômeno da tolerância imunológica induzida através das vias oral e nasal é bastante estudada (Mowat, 2001; Pereira \& Guedes, 2004). Contudo, a tolerância induzida através da via subcutânea tem sido pouco explorada, sendo escassas as referências na literatura. De acordo ainda com o resultado apresentado, o coelho imunizado, inicialmente com $200 \mu \mathrm{g}$ apresentou uma elevada taxa de anticorpos no soro préimune, sendo decorrente possivelmente, de uma préexposição do animal a antígenos similares ao da ricina, resultando em reação cruzada dos anticorpos. A ocorrência de reações cruzadas no método de ELISA, não é um evento raro de ocorrer, em virtude do mesmo ser altamente sensível, permitindo detecção a nível de nanogramas do antígeno. 


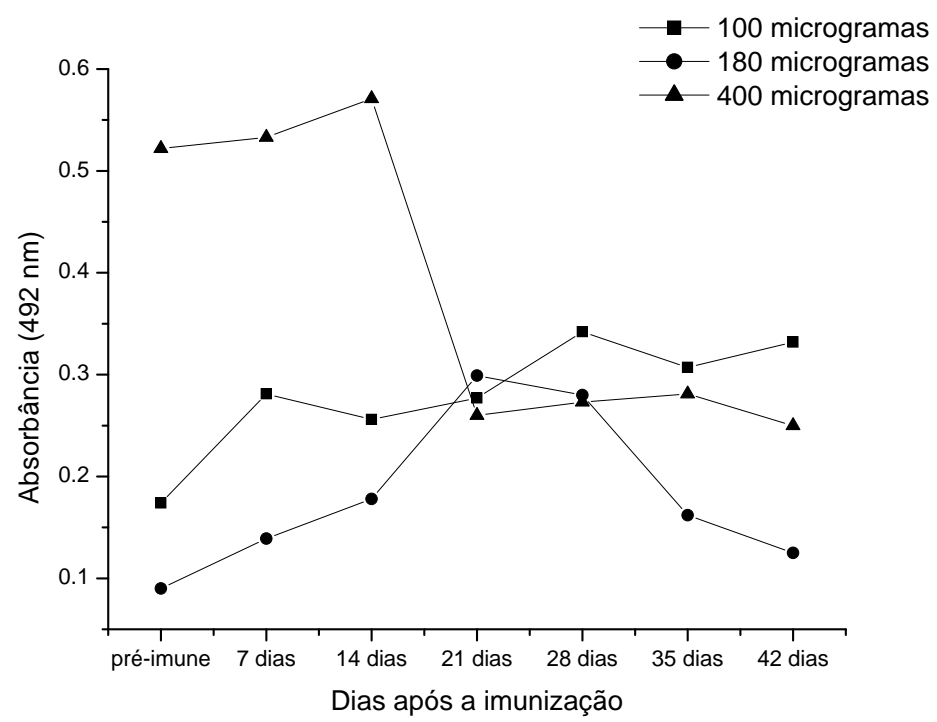

Figura 1 - Cinética de anticorpos de coelho, a partir de soro diluídos 1:100, após imunização com: $50 \mu \mathrm{g}$ de ricina e reforço com mesma quantidade ao $21^{\circ}$ dia; $90 \mu \mathrm{g}$ de ricina e reforço com mesma quantidade ao $21^{\circ}$ dia; $200 \mu \mathrm{g}$ de ricina e reforço com mesma quantidade ao $21^{\circ}$ dia.

Quando a dose de imunização foi reduzida de $400 \mu \mathrm{g}$ para $180 \mu \mathrm{g}$, observa-se que ocorreu uma resposta imunológica primária tardia, apresentando um pico máximo de produção de anticorpos aos 21 dias, após a imunização. Por outro lado, após o reforço aos 21 dias, não ocorreu uma elevação na produção de anticorpos (Figura 1). Por outro lado, quando o animal foi imunizado com a dose de $100 \mu \mathrm{g}$ de ricina (Figura 1), observa-se a indução de uma resposta imunológica primária com elevação da síntese de anticorpos específicos no $7^{\circ}$. Após o reforço, houve um estímulo satisfatório na produção de anticorpos, mantendo-se estável até o final do experimento. Esses resultados indicam que a dose de $100 \mu \mathrm{g}$ (menor) foi a que apresentou a melhor resposta de síntese de anticorpos. Indicando que, no caso do método de imunização adotado, não são necessárias doses maiores do que $100 \mu \mathrm{g}$ de ricina.

Os soros coletados dos coelhos a cada sete dias foram diluídos a fim de se determinar o título dos anticorpos, ou seja, determinar até qual diluição os anticorpos são capazes de reagir com o antígeno imobilizado na placa $(0,3 \mu \mathrm{g})$. Para isso, os soros de cada sangria foram comparados ao préimune e aqueles que apresentaram absorbância acima do cut off foram considerados positivos para a reação antígeno-anticorpo. Na Tabela 1 são expostas as diluições estabelecidas de acordo com o cut off.

A determinação da sensibilidade do soro do coelho que recebeu $400 \mu \mathrm{g}$ ficou comprometida em virtude do mesmo ter apresentado reação no soro préimune e comportamento típico de tolerância imunológica, assim, a maior sensibilidade verificada foi para o soro de 14 dias, o qual apresentou reação até a diluição de 1:3200 (Tabela 1).

Os anticorpos do coelho que recebeu $180 \mu \mathrm{g}$ mostrou sensibilidade crescente para os soros coletados de 7 a 28 dias (Tabela 1). O soro de 35 dias reagiu até 1:1600 e o de 42 dias até 1:400.

A sensibilidade dos soros produzidos a partir da imunização com $100 \mu \mathrm{g}$ foi maior para o soro de 35 dias (1/12800), seguido pelos soros de 42 dias (1/6400), 28 dias (1/800), 7 dias (1/400), 21 dias (1:400), e 14 dias (1:200) (Tabela 1).

Os anticorpos policlonais comerciais importados foram fornecidos na concentração de $1 \mathrm{mg} / \mathrm{mL}$ e apresentaram reação com o antígeno até a maior diluição avaliada de 1:12.800. Os soros obtidos segundo a metodologia deste trabalho apresentaram, em determinados dias após a imunização, sensibilidade até a diluição de 1:12.800, apresentando sensibilidade similar à verificada pelos anticorpos comerciais, apesar de estarem diluídos no soro, evidenciando a viabilidade da técnica para a produção de anticorpos.

Pelos resultados através de teste de Western blotting provou-se que os anticorpos produzidos reconheceram especificamente a ricina nativa e desnaturada (Figura 2). 
Tabela 1 - Titulo dos anticorpos obtidos relacionados com o dia após a imunização e a dose de imunização.

\begin{tabular}{ccccccc}
\hline \multicolumn{7}{c}{ Dose $100 \mu \mathrm{g}$} \\
\hline Dias & 7 & 14 & 21 & 28 & 35 & 42 \\
Diluição & $1: 400$ & $1: 200$ & $1: 400$ & $1: 800$ & $1: 12800$ & $1: 6400$ \\
\hline \multicolumn{7}{c}{ Dose $180 \mu \mathrm{g}$} \\
\hline Dias & 7 & 14 & 21 & 28 & 35 & 42 \\
Diluição & $1: 800$ & $1: 3200$ & $1: 6400$ & $1: 12800$ & $1: 1600$ & $1: 400$ \\
\hline \multicolumn{7}{c}{ Dose $400 \mu \mathrm{g}$} \\
\hline Dias & 7 & 14 & 21 & 28 & 35 & 42 \\
Diluição & $1: 100$ & $1: 3200$ & $1: 100$ & $1: 100$ & $1: 100$ & $1: 100$ \\
\hline
\end{tabular}

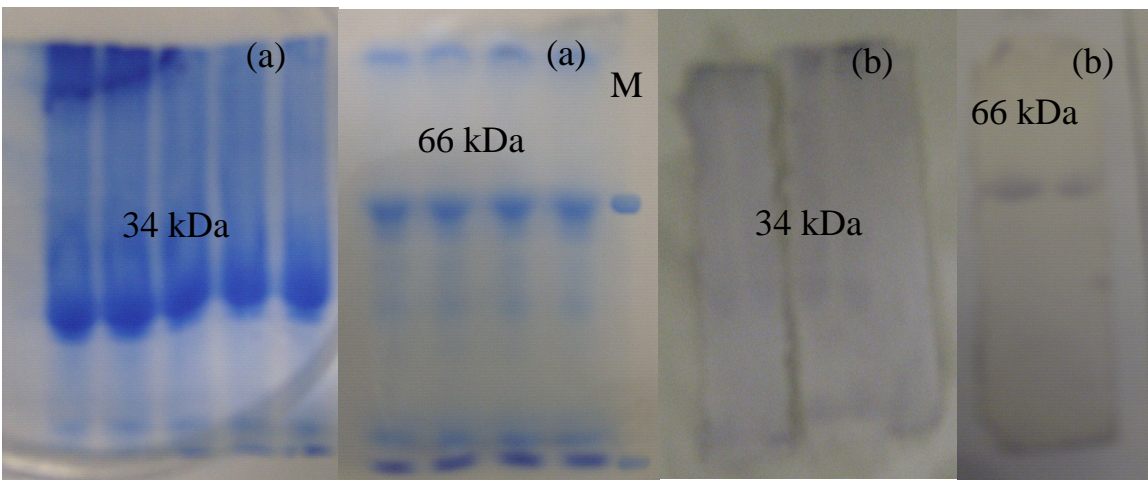

Figura 2 - Extrato proteico de torta de mamona obtidas em gel de poliacrilamida (a), sobre condições desnaturantes (esquerda) e não desnaturantes (direita), (b) resultados de Western blotting sobre condições desnaturantes (esquerda) e não desnaturantes (direita). Com a letra M faz-se referência ao marcador molecular- BSA (66 kDa).

Com os resultados obtidos pela técnica de Western blotting indicaram-se que os anticorpos produzidos são eficientes na detecção da ricina, contudo, para o fim a que está sendo proposto neste trabalho, detecção de ricina em torta de mamona destoxificada por tratamento térmico, os ensaios sorológicos baseados em anticorpos policlonais não são adequados, tendo em vista que esses não diferenciaram a ricina nativa e desnaturada. No entanto, outros métodos de destoxificação da torta de mamona como hidrólise enzimática podem desnaturar essa proteína tóxica de forma que não sejam reconhecidas pelos anticorpos policlonais. Considerando o tratamento térmico como método de destoxificação da torta de mamona, recomenda-se que sejam produzidos anticorpos monoclonais a partir de sítios específicos da proteína que sofram alteração na sua conformação, quando desnaturada. Por outro lado, a metodologia de produção de anticorpos policlonais pode ainda ser aplicada para fins de detecção de ricina em produtos que não são submetidos à inativação da proteína por tratamento térmico e não necessitam dessa distinção, como, por exemplo, para fins de bioterrorismo (Casadevall, 2002).

\section{CONCLUSÕES}

Os anticorpos policlonais produzidos reconheceram seletivamente a ricina no extrato de mamona.

Os anticorpos policlonais não foram capazes de diferenciar a ricina na sua forma nativa ou desnaturada por tratamento térmico. Esse fato torna inadequada a aplicação direta de anticorpos policlonais para análises de detecção de traços de ricina em torta de mamona destoxificada por tratamento térmico.

A dose recomendada para produção dos anticorpos policlonais anti-ricina, utilizando poliacrilamida como adjuvante é $100 \mu \mathrm{g}$ da lectina.

\section{AGRADECIMENTOS}

Á Embrapa Algodão, pelo fornecimento das sementes de mamona da cultivar Nordestina e a FINEP e Embrapa, pelo suporte financeiro. 


\section{REFERÊNCIAS BIBLIOGRÁFICAS}

AMERO, S.A.; JAMES, T.C.; ELGIN, S.C.R. Production of antibodies using proteins in gel bands. Methods in Molecular Biology, v.32, p.401406, 1994.

ANANDAN, S.; ANIL KUMAR, G.K.; GHOSH, J.; RAMACHANDRA, K.S. Effect of different physical and chemical treatments on detoxification of ricin in castor cake. Animal Feed Science and Technology, v.120, n.1, p.159-168, 2005.

APPUKUTTAN, P.S.; SUROLLA, A.; BACHHAWAT, B.K. Isolation of two galactose-binding proteins from Ricinus communis by affinity chromatography. Indian Journal of Biochemistry \& Biophysics, New Delhi, v.14, n.4, p.382-384, 1977.

ASLANI, M.R.; MALEKI, M.; MOHRI, M.; SHARIFI, K.; NAJJAR-NEZHAD, V.; AFSHARI, E. Castor bean (Ricinus communis) toxicosis in a sheep flock. Toxicon, v.49, n.3, p.400-406, 2007.

AUDI, J.; BELSON, M.; PATEL, M.; SCHIER, J.; OSTERLOH, J. Ricin poisoning: a comprehensive review. American Medical Association, v.294, n.18, p.2342-2351, 2005.

BARNES, D.J.; BALDWIN, B.S.; BRAASH, D.A. Degradation of ricin in castor seed meal by temperature and chemical treatment. Industrial Crops and Products, v.29, n.2/3, p.509-515, 2009.

BESERRA JÚNIOR, J.E.A.; MARQUES, M.M.M.; BARGUIL, B.M.; LOPES JUNIOR, C.A.F.; GUEDES, M.I.F. Imunogenicidade de proteínas do capsídeo do Cowpea severe mosaic virus (CPSMV). Ciência e Agrotecnologia, Lavras, vol.33, n.1, p.98-104, jan./fev., 2009.

BRITO, M. de F.; TOKARNIAS, C.H. Intoxicação experimental pelas sementes trituradas de Ricinus communis (Euphorbiaceae) em coelhos. Pesquisa Veterinária Brasileira, Brasília, v.16, n.4, p.1-7, 1996.

CASADEVALL, A. Passive antibody administration (immediate immunity) as a specific defense against biological weapons. Emerging Infectious Diseases Journal, v.8, n.8, p.833-41, 2002.

COSTA, F.X.; SEVERINO, L.S.; BELTRÃO, N.E. de M.; FREIRE, R.M.M.; LUCENA, A.M.A.; GUIMARÃES, M.M.B. Avaliação de teores químicos na torta de mamona. Revista de Biologia e Ciências da Terra, v.4, n.2, 2004. Disponível em: 〈http://eduep.uepb.edu.brir' rbct/sumarios/pdf/tortamamona.pdf 2009.

FRANZ, D.R.; JAAX, N.K. Ricin toxin. In: TEXTBOOKS OF MILITARY MEDICINE. Medical aspects of chemical and biological warfare. Washington: Department of the Army, Office of the Surgeon General, 1997. p.631-642.

GARDNER JUNIOR, H.K.; AQUIN, E.L. d'; KOLTUN, S.P.; McCOURTNEY, E.J.; VIX, H.L.E. Detoxification and deallergenization of castor beans. The Journal of the American Oil Chemists Society, v.37, p.142-148, 1960.

HOYNE, G.F.; CORSIN-JIMENEZ, M.; TAN, K.; WAHL, K.; STEWART, M.; HOWIE, S.E.M. Immunological tolerance to inhaled antigen. American Journal of Respiratory and Critical Care Medicine, v.162, n.4, p.S169-S174, 2000.

JANEWAY, C.A.; TRAVERS, P.; WALPORT, M.; SHLMCHIK, M.J. Imunobiologia: o sistema imunológico na saúde e na doença. Porto Alegre: Artmed, 2007. 848p.

LIPPS, B.V. Production of polyclonal antibodies in mice against cobratoxin, botulinum toxin and ricin without altering their toxicity or use of adjuvant. Journal of Natural Toxins, v.10, n.1, p.27-32, 2001.

LORD, J.M.; ROBERTS, L.M.; ROBERTUS, J.D. Ricin: structure, mode of action, and some current applications. The FASEB Journal, v.8, n.2, p.201-208, 1994.

MOWAT, A.M. Oral tolerance and regulation of immunity to dietary antigens. In: OGRA, P.L.; STROBER, W.; MESTECKY, J.; LMM, M.E.; BIENENSTOCK, J.E. (Eds.). Handbook of mucosal immunity. San Diego: Academic, 1994. p.185-201. 
OGUNNIYI, D.S. Castor oil: a vital industrial raw material. Bioresource Technology, v.97, n.9, p.10861091, 2006

OLSNES, S.; KOZLOV, J. Ricin. Toxicon, v.39, n.11, p.1723-1728, 2001.

PEREIRA, M.R.P.; GUEDES, M.I.F. Imunização oral e alergenecidade induzida por proteínas de sementes de
Lablad purpureus (L) Sweet em camundongos e sua modulação por carboidratos. Revista Brasileira em Promoção da Saúde, v.18, n.2, p.90-97, 2005.

TOWBIN, J.; STAEHELM, T.; GORDON, J.

Electrophoretic transfer of proteins from polyacrylamide gels to nitrocellulose sheets: procedure and some applications. Proceedings of the National Academy of Sciences, Washington, v.76, p.4350-4354, 1979. 